\title{
Distribution and growth in an economy with limited needs. ${ }^{1}$
}

Variable markups and "The End of Work".

\author{
Gilles Saint-Paul \\ GREMAQ, IDEI, Université des Sciences Sociales de Toulouse \\ CEPR, IZA, and CES
}

March 16, 2005

\footnotetext{
${ }^{1}$ I am grateful to Josef Falkinger, Reto Foellmi, Josef Zweimüller, Samuel Bentolila, Richard Nahuis, Michael Funke, Andrew Scott, two anonymous referees, and to participants in the NBER Summer Institute workshop on income distribution, Cambridge, July 2001, the Latin American meeting of the econometric society, Buenos Aires, July 2001, and the CREI conference on unemployment, Barcelona, October 2001, and a seminar in Zürich university, March 2002, for helpful comments and suggestions.E-mail: gilles.saint-paul@univ-tlse1.fr
} 
"The whole system of capitalist production is based on the fact that the workman sells his labour-power as a commodity. Division of labour specialises this labour-power, by reducing it to skill in handling a particular tool. So soon as the handling of this tool becomes the work of a machine, then, with the use-value, the exchange-value too, of the workman's labour-power vanishes; the workman becomes unsaleable, like paper money thrown out of currency by legal enactment. That portion of the working-class, thus by machinery rendered superfluous, i.e., no longer immediately necessary for the self-expansion of capital, either goes to the wall in the unequal contest of the old handicrafts and manufactures with machinery, or else floods all the more easily accessible branches of industry, swamps the labour-market, and sinks the price of labour-power below its value. "- Karl Marx, Das Kapital, Vol. 1, Ch. 15.

Marx's vision of technical progress as an instrument of capitalist exploitation that raises profits at the expense of wages has been invalidated by more than a century of improvements in living standards. But in the last few decades inequality has risen in the United States, average real wages have stagnated, and have indeed fallen for the poorest, bringing up again the question of whether technical change may harm workers.

One difference between this recent process and Marx's vision is that it does not only benefit capitalists, but also 'knowledge' workers specialized in the production of new blueprints and ideas. These people are able to gain a lot in terms of income, because many of the new goods they help to invent (media, software, records, etc...) are very cheap to produce, and therefore cover a very large market. ${ }^{1}$ Thus, some authors such as Robert Reich (1992) envision a society with a widening cleavage between "symbol manipulators" and ordinary workers. However, Reich is silent about the mechanism by

\footnotetext{
${ }^{1}$ See Rosen (1981) for an analysis of this "economics of superstars". The effects studied here are somewhat related, but different.
} 
which high productivity transfers income from the latter to the former.

A related view, which goes back to early critiques of consumer's society, is that unless new needs are created, productivity growth is bound to make workers useless. This view is exemplified in a book by Rifkin (1996) called The End of Work. Indeed, one characteristic of modern Western society is the saturation of many needs; households are loaded with consumer appliances, vehicles, clothes, and so forth. A visitor from a low income country would be struck by the proliferation of shops specialized in plainly useless goods. Such bliss is permitted by the very low production costs that secular productivity growth has generated. This phenomenon is bound to accelerate with the growing share of intangible goods such as music, software, or video games, whose production cost is very small. But again, here, there lacks an explicit economic mechanism which would explain why such saturation would be associated with declining wages or employment. First, it is not clear why consumption would not adjust so as to absorb increases in productive capacity; second, more affluence intuitively means higher living standards.

This paper develops an orthodox economic model where a society which resembles Reich's and Rifkin's speculations actually arises ${ }^{2}$. In this model, needs are limited in that utility from consuming any given good is bounded. As in Dixit and Stiglitz (1977), each good is a differentiated brand produced by a monopoly. Contrary to Dixit-Stiglitz, demand is not isoelastic, because of limited needs. A central result is that beyond some point productivity improvements reduce wages - if properly measured as the return to production work - in a fashion echoing Marx's gloomy predictions about the pauperisation of proletariat. In contrast, such improvements boost the profits and market values of firms. If goods are invented by workers specialized in $\mathrm{R}$ and $\mathrm{D}$, then these workers' income goes up as well.

Bounded needs are intimately linked to the negative effect that productivity eventually has on wages. This is because when utility is bounded,

\footnotetext{
${ }^{2} \mathrm{~A}$ very different attempt to rationalize criticisms of mass consumption societies can be found in Benhabib and Bisin (2001).
} 
the price elasticity of demand for a given good falls to zero with the average consumption of that good. Consequently, if the good is produced by a monopolist, the markup over marginal cost will become very large as consumption goes up. Given the number of goods, general productivity growth raises consumption of each good, pushing markups to infinity. In general equilibrium, this means that real wages end up falling to zero. That is, more than $100 \%$ of the growth in GDP permitted by productivity growth is appropriated by profits, i.e. by those who own property rights over blueprints.

For tractable bounded utility functions, such as quadratic or exponential ones, I show that as productivity in the material goods sector goes up, the economy first goes through a "Solovian" zone where wages increase, and then reaches a "Marxian" zone where further productivity growth reduces wages-because markups increase more than proportionately. This fatality is inevitable unless new goods are being introduced. To consider that possibility, I assume (realistically, in my view) that while utility from any given good is bounded, new goods are always equally valued by consumers regardless of the initial number of goods. An increase in the number of varieties reduces consumption of any given good, thus moving the economy away from the low-elasticity, saturation zone. Therefore, the question is: do productivity increases result in the introduction of a sufficient number of additional goods in order to prevent wages from falling?

The rise in profitability brought about by productivity growth increases the incentives for innovation as well as the wage of research labor. Thus, labor is reallocated away from production into knowledge, which tends to increase the number of goods; this in turns reduces consumption of each good, moving it away from the saturation point, so that elasticity rises and markups fall. Therefore, these effects tend to offset an initial reduction in wages. Whether or not a Marxian zone (where absolute wages fall) exists then depend on how strong these effects are. But the wages of production workers relative to knowledge workers still unambiguously falls.

This picture of technical change which raises inequality and possibly low- 
ers absolute wages at the bottom of the distribution of earnings, is reminiscent of the US economy in the last three decades. The empirical literature has established that inequality has increased, that wages have stagnated overall, and that they have actually fallen for the least skilled. It has concluded that this is probably explained by a relative demand shift due to skill-biased technical progress. ${ }^{3}$ One key contribution of the present paper is to show that even though skill-bias may not be directly embodied in technology, productivity may increase inequality because of the general equilibrium interaction between imperfect competition and bounded needs. General productivity growth increases the (absolute and relative) returns to creativity, which is indexed on profits and thus positively linked to markups. If more skilled workers have a comparative advantage in these activities, then inequality will indeed increase.

This mechanism is quite different from the ones that have been discussed in the recent literature (Zeira (1998), Krusell et. al. (2000), Caselli (2000), Acemoglu (1999,2000), or Beaudry and Green (2003)), which has emphasized that new technologies result in the allocation of more capital to skilled workers at the expense of unskilled ones. It is also different from the one studied by Cohen and Saint-Paul (1994), who, following Baumol (1967,1985), show that if sectors are complementary to each other and labor is imperfectly mobile, technical progress in a given sector may harm workers in that sector if productivity remains the same in the rest of the economy. ${ }^{4}$

While one does not want to dismiss other mechanisms as contributors to the observed rise in inequality in the United States, particularly because not all of it may be due to a greater return to creativity, the phenomenon studied here may also have played a role. In particular, Morrison (1992), has found an upward trend in price-costs markups in both the US and Japan

\footnotetext{
${ }^{3}$ See Katz and Murphy (1992), Juhn, Murphy and Pierce (1993) and Levy and Murnane (1992).

${ }^{4}$ Falkinger $(1990,1994)$ and Foellmi and Zweimüller (2002) study the reverse problem, i.e., the impact of income distribution on innovation in models of hierarchical needs and nonlinear Engel curves.
} 
over the relevant period. ${ }^{5}$ Also, in section 3.3 we find that increases in the ratio between consumption per capita and the number of brands tend lo lead increases in inequality in the eighties and nineties.

The paper is organized as follows: in section 1, I study a static general equilibrium model with a fixed number of goods each produced by a monopoly, and bounded utility. I show that the response of wages to productivity is hump-shaped. At high productivity levels the economy eventually reaches a "Marxian" zone where wages fall in response to productivity improvements. Section 2 studies the consequences of allowing the number of goods to be endogenous, by assuming that labor can be allocated between production and invention-which also allows to study the distribution of wages when workers have different skills and may elect to become production workers or knowledge workers. It also studies balanced growth paths when productivity grows in the innovation sector as well as in the production sector. Section 3 discusses some applications of the model, namely the effect of productivity growth on employment when labor is unionized, and the effect of international trade on wages ${ }^{6}$. It also looks at comovements between inequality and consumption per product, and finds that they are broadly consistent with the model. Finally, Section 4 concludes.

\section{The effect of total factor productivity on wages in a static general equilibrium model of monopolistic competition.}

In this section, we analyze the determinants of markups and wages in a static model with a fixed number of goods. We show that if utility derived from any given good is bounded, then wages eventually fall in response to increases in total factor productivity.

\footnotetext{
${ }^{5}$ See also Nevo (1999), who finds high markups in ready to eat cereals, a banal good of which many households are not far from being saturated.

${ }^{6}$ In particular, I show that wages in the poorest country may fall in response to greater openness, a result reminiscent of a recent paper by Matsuyama (2000).
} 


\subsection{Basic setting}

Let us start with a static model with a fixed, exogenous number of goods.

Consider an economy with a continuum of goods of mass $N$ and a continuum of consumers of mass 1 . Together, these consumers supply an inelastic quantity of labor equal to $L$. They potentially differ in their labor endowment and in the fraction of corporate capital that they own, in a way which need not be specified yet. The utility of consumer $j$ is given by

$$
u_{j}=\int_{0}^{N} v\left(c_{i j}\right) d i
$$

where $c_{i j}$ is agent $j$ 's consumption of good $i$ and $v$ is given by

$$
v(c)=1-e^{-b c} .
$$

In that formulation, cardinal utility is bounded, contrary to what one would get under the usual isoelastic case $v(c)=c^{\alpha}, \alpha \geq 0$. As shown and discussed below, this feature has important implications. Utility also satisfies $u(0)=0$, so that it is invariant to introducing new goods that are consumed in zero quantity.

Let $R_{j}$ denote the income of consumer $j$, which is the sum of his labor income and his dividend income. People maximize their utility function (1) subject to their budget constraint

$$
\int_{0}^{N} p_{i} c_{i j}=R_{j}
$$

where $p_{i}$ denotes the price of good $i$. The resulting demand function is:

$$
c_{i j}=\max \left(-\frac{1}{b} \ln \frac{p_{i}}{b}+\frac{\int_{0}^{N} \frac{p_{m}}{b} \ln \frac{p_{m}}{b} d m+R_{j}}{\int_{0}^{N} p_{m} d m} ; 0\right)
$$

Assuming $c_{i j}>0$ for all $i, j$, it can be aggregated across consumers to get the aggregate demand for good $i$ :

$$
c_{i}=-\frac{1}{b} \ln \frac{p_{i}}{b}+\frac{\int_{0}^{N} \frac{p_{m}}{b} \ln \frac{p_{m}}{b} d m}{\int_{0}^{N} p_{m} d m}+\frac{Y}{\int_{0}^{N} p_{m} d m},
$$


where $c_{i}=\int_{0}^{1} c_{i j} d j$ is total consumption of good $i$ and $Y=\int_{0}^{1} R_{i j} d j$ is total income. Note that demand does not depend on the distribution of income, a convenient feature given this paper's focus on the effect of pricing and productivity on income distribution, rather than the converse. ${ }^{7}$

Each good is produced by a monopoly using labor as the only input. One unit of labor produces $a$ units of a good. The monopoly maximizes its profit $p_{i} c_{i}-w c_{i} / a$, where $w$ is the wage, subject to (4). As each monopoly is atomistic, it neglects the effect of its price on the integral in the RHS of (4). Consequently, its optimal price, assuming it is in the zone where all consumers consume all goods, is determined by the first-order condition

$$
-\frac{1}{b} \ln \frac{p_{i}}{b}+\frac{\int_{0}^{N} \frac{p_{m}}{b} \ln \frac{p_{m}}{b} d m}{\int_{0}^{N} p_{m} d m}+\frac{Y}{\int_{0}^{N} p_{m} d m}=\frac{p_{i}-w / a}{b p_{i}}
$$

We have one degree of freedom in normalizing prices. Since all prices are equal by symmetry, it is natural to normalize them to one. Note then that one has to be cautious in interpreting wages, as welfare may go up if $w$ falls but $N$ rises at the same time: Income still represents purchasing power in physical terms, but fails to capture the effects of greater diversity on utility. ${ }^{8}$

Given that $p_{i}=1$, Equation (5) then boils down to an equation linking wages with aggregate income:

$$
w=a(1-b Y / N)
$$

How is then $R$ determined? Aggregating budget constraints, we get that the consumption of each good is given by

$$
c_{i}=c=Y / N, \forall i .
$$

\footnotetext{
${ }^{7}$ One can show that demand functions can be aggregated into a function of aggregate income and prices, only for power, quadratic, and exponential utility functions.

${ }^{8}$ Under homothetic preferences, one could normalize the aggregate price level to one, and given that its definition reflects the value of product diversity, wages would truly reflect welfare. Here, however, indirect utility cannot be written as $R / p$.
} 
Finally, equilibrium in the labor market implies that $N c=a L$, so that we simply have

$$
Y=a L
$$

Substituting into (6) we get the formula determining wages:

$$
w=a(1-b a L / N)
$$

The most interesting property of (8) is that $w$ is not monotonous in a. Rather, it is hump-shaped, as illustrated in Figure 1. As productivity increases, the economy gradually moves from a Solovian zone where productivity improvements raise wages to a Marxian zone where they are more than entirely appropriated by profits and wages actually fall. There exists a critical level of productivity where wages are exactly equal to zero, given by $a=N / b L$.

\subsection{Discussion}

The paradoxical existence of a Marxian zone, where wages fall with productivity, comes from the limited needs and imperfect competition properties of the model. In equilibrium, wages are equal to the product of productivity $a$ and the inverse markup $1-b a L / N$. Thus, when productivity goes up, so does the markup.

Why? With $v(c)=1-e^{-b c}$, the local price elasticity of demand for a good consumed in quantity $c$ is given by $1 / b c$. Elasticity is therefore decreasing, and converging to zero, as consumption goes up. That is, while people are willing to pay less for a good, they are also locally less sensitive to its price. That is the key difference between the bounded utility considered here and the usual isoelastic formulation. Consequently, the markup goes up with aggregate income, and therefore with productivity. If markups were constant, productivity increases would instead generate proportional increases in wages. 
The end point of the Marxian zone, where wages become equal to zero, correspond to the point where markups are infinite, i.e. the elasticity of demand for each good is equal to one ${ }^{9}$.

One may wonder whether the Marxian zone is an artifact of the specification. Consider, alternatively, the case where $v$ is quadratic:

$$
v(c)=c(1-b c / 2)
$$

Using the same steps as in the previous subsection, one may easily check that equilibrium wages are given by

$$
w=a \frac{N-2 b a L}{N-b a L}
$$

This function is again hump-shaped: conclusions are the same as in the exponential case. Next, consider any general utility function $v(c)$ which is bounded. If a consumer consumes $c$ units of a good, the price elasticity of demand is given by $\eta=\left|v^{\prime}(c) / c v^{\prime \prime}(c)\right|$. One can show that for any bounded utility, as $c$ goes up the elasticity $\eta=\left|v^{\prime}(c) / c v^{\prime \prime}(c)\right|$ ends up being lower than any $\varepsilon>1$, which means that we can find arbitrarily large values of $c$ such that the associated markup $\eta /(\eta-1)$ is arbitrarily large. ${ }^{10}$ Thus, by continuity, if needs are bounded, if we start from an equilibrium with a positive wage and let productivity grow, a Marxian zone necessarily arises.

To conclude, while a single hump is an attractive feature of the exponential (or quadratic) specifications, the existence of a Marxian zone does not rely on any specific utility function, it is a necessary consequence of bounded needs.

\footnotetext{
${ }^{9}$ Thus, at that point, $c=1 / b$,i.e. $a L / N=1 / b$.

${ }^{10}$ The proof is as follows. Assume $-v^{\prime} / c v^{\prime \prime}>\varepsilon>1$ for all $c \geq c_{0}$. Then integrating the inequality $-v^{\prime \prime} / v^{\prime}<1 /(\varepsilon c)$ between $c$ and $c_{0}$ yields $\ln v^{\prime}(c)>\ln v^{\prime}\left(c_{0}\right)-\left(\ln c-\ln c_{0}\right) / \varepsilon$, i.e. $v^{\prime}(c)>v^{\prime}\left(c_{0}\right)\left(c / c_{0}\right)^{-1 / \varepsilon}$. Integrating again, we get $v(c)>v^{\prime}\left(c_{0}\right) / c_{0}^{-1 / \varepsilon} \frac{\varepsilon}{\varepsilon-1}\left(c^{1-1 / \varepsilon}-c_{0}^{1-1 / \varepsilon}\right)$, which is not bounded.
} 
Note that when $a$ goes up, wages fall, or at most increase less than proportionally to GDP, so that profits must increase more than proportionally. Formally, profits are given by $\pi_{i}=\left(p_{i}-w / a\right) c_{i}$, i.e.

$$
\pi_{i}=\pi=b\left(\frac{a L}{N}\right)^{2}
$$

They increase more quickly than $a$ and account for $100 \%$ of GDP when one reaches the end of the Marxian zone at $a=N / b L$. Productivity growth redistributes income from workers to owners of firms. Markups go up because consumers are less elastic on average, but a person with just labor income would become more elastic if the economy is in the Marxian zone. Reduced elasticity from "capitalists" who get richer more than offsets increased elasticity from "workers" who get poorer.

Another aspect is that wages go up with the number of varieties $N .{ }^{11}$ As $N$ goes up, less is consumed of each good, which pushes consumers further away from their maximum utility and increases the elasticity of demand for each good, thus reducing markups and raising equilibrium wages. Hence introducing new goods "de-banalizes" consumption and runs against the Marxian zone.

\subsection{Some technical problems}

In the preceding results, we have assumed some arbitrary degree of heterogeneity across agents, and characterized a symmetrical equilibrium where all agents consume all goods. The above results then hold conditional on the existence of such a symmetrical equilibrium.

In fact, the existence of a symmetrical equilibrium is far from obvious, especially in the quadratic and exponential cases that we have just discussed. The reason is that in both cases, the Inada conditions are not satisfied, so

\footnotetext{
${ }^{11}$ Note that since our price normalization implies that wages are expressed in physical terms, that effect is different from the effect of the number of goods on utility due to the taste for variety.
} 
that it may be optimal for a consumer not to consume a good at all if the price of that good is large enough compared to the prices of other goods. Of course, in symmetrical equilibrium, all agents consume all goods, unless some agents have zero income. But a firm can consider deviating by charging a high price and putting itself in a zone where only consumers richer than a given income level would consume its good. ${ }^{12}$ While (5) is a necessary condition for an equilibrium where all agents consume all goods, it does not rule out such a possibility. ${ }^{13}$

To solve this problem, one has several options. The first one is to assume a representative agent (or, equivalently, that all agents have purchased perfect insurance prior to the realization of inequality), and study the factor rather than personal distribution of income. The second one is to impose restrictions on the distribution of income such that a symmetrical equilibrium exists. The following proposition guarantees the existence of a symmetrical equilibrium with strictly positive wages $^{14}$ :

Proposition 1 - Assume income $R$ is distributed among agents with c.d.f. $G(R), G^{\prime}=g$. Assume preferences are given by (2). Let $Y=\int_{0}^{+\infty} g(R) R d R$. Assume $Y<N / b$. If

$$
\forall z>0, E(R \mid R \geq z) \leq z+Y
$$

then there exists a symmetrical equilibrium where all firms charge $p_{i}=1$ and wages are given by (6).

\section{PROOF - See Appendix}

Condition (10), which is satisfied for an exponential distribution $g(R)=$ $\gamma e^{-\gamma\left(R-R_{0}\right)}$, makes it unprofitable for an individual producer to deviate from

\footnotetext{
${ }^{12} \mathrm{I}$ am indedbted to Josef Zweimuller and Reto Foellmi for bringing this point to my attention.

${ }^{13} \mathrm{~A}$ milder problem is that even if all consumers consume all goods, the first-order condition (5) tells us nothing about whether this is actually a global optimum for each firm; and it is not obvious to establish such a property, as the profit function $\pi(p)$ of a monopoly is never concave.

${ }^{14}$ For $a L>N / b$, one may construct under-employment equilibria with zero wages; these are not particularly plausible, so we abstract from them.
} 
a symmetrical equilibrium by charging a higher price than others and exclude some consumers from its market. Intuitively, it tells us that the average income of consumers above a given level should not increase "too fast" with that level - otherwise, firms are tempted to focus on rich consumers and charge high prices. While Proposition 1 is a partial equilibrium result, since it takes as given the distribution of income $G($.$) which is endogenous, there$ is no difficulty in computing $G()$ from the distribution of firm ownership and labor endowments, since equilibrium profits and wages can be computed straightforwardly from (8) and (9). As checking directly for (10) may be cumbersome, we provide another condition which is more easy to check:

Lemma 1 - A sufficient condition for (10) to hold is

$$
\frac{g(v+z)}{1-G(z)} \leq g(v), \forall v, z
$$

PROOF-See Appendix.

\section{Extensions}

We now analyse two key extensions of the model. The first one endogenizes the number of goods, by assuming workers have different skills and elect between production work and innovation. The second one allows for longterm balanced growth, by allowing the cost of inventing new goods to fall with time.

\subsection{Endogenizing the number of goods and the personal distribution of income}

The preceding discussion implies that under the "limited needs" assumption, an increase in productivity increases profits more than proportionally, and wages less than proportionally. Consequently, incentives to work in the production sector fall relative to incentives to introduce new goods. If workers can elect between working as "productive workers" vs. working as "creative 
workers" - i.e. inventing new goods - then an increase in total factor productivity will trigger labor reallocation from the productive to the creative sector. The number of goods rises, consumption of each good falls, which pushes markups down and wages up. Intuitively, if the supply response of creative workers is sufficiently elastic, this effect can be strong enough so as to offset the direct negative effect of productivity on wages. In that case there is no Marxian zone and all agents benefit from productivity growth. If the supply response is insufficient, then wages fall and the Marxian zone still exists. However, in both cases, as we shall see, relative inequality goes up.

To analyze this point, we extend the model so as to endogenize the allocation of labor between production and innovation. This will also be useful to analyze the effect of productivity growth on the distribution of wages between "creative" and "productive" workers.

We take the preceding model as our basis, and now endogenize both $L$ and $N$. There exists a continuum of workers of mass 1 indexed by $s \in[0,1]$. $s$ denotes the ranking of a worker in the distribution of skills. A worker with skill $s$ is endowed with $l(s)$ units of productivity and $h(s)$ units of creativity. Both $l$ and $h$ are increasing and differentiable. Furthermore, the ratio $h(s) / l(s)$ is assumed to be increasing with $s$. Thus creativity is more sensitive to skill than productivity, implying that the most skilled workers will sort themselves into the creative occupation.

Workers must elect between working in the production sector, in which case they supply $l(s)$ units of labor and earn $w l(s)$, and working in the $\mathrm{R}$ $\& \mathrm{D}$ sector - where goods are invented - where they earn $\omega h(s) .{ }^{15} \mathrm{I}$ assume free entry of firms in the R \& D sector, so that all profits are appropriated by productive workers. Assuming that $h$ units of creativity allow to invent $h$ goods, then in equilibrium one must have $\omega=\pi$. Both $\pi$ and $w$ remain determined by (8) (9) as long as the economy is in a symmetrical equilibrium.

\footnotetext{
${ }^{15}$ In this static model, the research input needed to invent a good and consumption of that good coincide in time.
} 
Clearly, in equilibrium, there exists a critical skill $s^{*}$ determined by

$$
h\left(s^{*}\right) / l\left(s^{*}\right)=w / \omega,
$$

and such that all workers above $s^{*}$ work in $\mathrm{R} \& \mathrm{D}$, and all the others in the production sector. Consequently, we must have

$$
\begin{aligned}
N & =\int_{s^{*}}^{1} h(s) d s=N(w / \omega), N^{\prime}(.)<0 ; \\
L & =\int_{0}^{s^{*}} l(s) d s=L(w / \omega), L^{\prime}(.)>0, L(0)=0
\end{aligned}
$$

The model is then closed by determining the equilibrium ratio $w / \omega$, which must be consistent with the determination of wages and profits. Using again (9) and (8) we get

$$
\frac{w}{\omega}=\frac{(N(w / \omega)-b a L(w / \omega))}{b a L(w / \omega)^{2}} N(w / \omega) \equiv v(\omega)
$$

As shown on Figure 2, that uniquely determines the price of productivity relative to creativity, $w / \omega$. Furthermore, an increase in total factor productivity a clearly reduces the equilibrium level of $w / \omega$, and that is again due to the rise in the markup.

The distribution of log wages is depicted on Figure 3. Because of the assumption that $h($.$) rises faster than l($.$) with skills, there is a jump in the$ return to skill around the critical level $s^{*}$. Figure 4 shows the effect of an increase in $a$ : inequality between creative and productive workers goes up and there is reallocation of labor away from the production sector into the $\mathrm{R}$ \& D sector. In Figure 4a, the absolute wage of productivity falls (Marxian zone); in Figure 4b, it does not (Solovian zone). As stated above, both the reduction in labor supply and the increase in the number of varieties tend to push wages up. This makes the Marxian zone less likely, the stronger the response of labor supply to the fall of $w / \omega .{ }^{16}$ However, as long as the ratio

\footnotetext{
${ }^{16}$ The precise condition is

$$
\begin{array}{r}
0>\frac{d w}{d a} \\
=1-2 b a L-b a^{2} L^{\prime} \frac{d(w / \omega)}{d a}+b a^{2} \frac{L N^{\prime}}{N^{2}} \frac{d(w / \omega)}{d a},
\end{array}
$$
}


$L / N$ falls less than proportionally to $a,(8)$ implies that a Marxian zone will eventually arise.

To summarize: endogenizing the allocation of labor between production and innovation does not affect the result that an increase in total factor productivity increases inequality between profits/creative workers and wages/productive workers. It predicts that product variety goes up, and the supply of productive labor down, when TFP goes up; this tends to push wages up, but the effect need not be strong enough to preclude a Marxian zone.

In this discussion, we have implicitly assumed that a symmetrical equilibrium exists. Is that granted? It clearly depends on the properties of the $h($.$) and l($.$) functions. In the Appendix, we show that if the l($.$) and h($. functions have the following functional form:

$$
\begin{aligned}
& l(s)=l_{0}-\frac{\ln (1-s)}{\beta} \\
& h(s)=h_{0}-\frac{\ln (1-h)}{\gamma},
\end{aligned}
$$

then Lemma 1 applies, so that there exists a symmetrical equilibrium.

\subsection{Welfare}

We have so far analyzed the effect of productivity on wages. Wages are different from welfare for two reasons: first, individuals own claims on firms in addition to labor; second, the number of goods may change and it directly affects welfare because of the taste for variety.

One can check that the utility of a person owning $l$ units of labor is given

where $\frac{d(w / \omega)}{d a}$ is given by

$$
\frac{d(w / \omega)}{d a}=-\frac{b L+b L^{2} w / \omega}{b a L+2 b a L L^{\prime} w / \omega-N^{\prime}+b a L^{\prime}} .
$$


by

$$
u(l)=N\left(1-e^{-b w l / N}\right) .
$$

Consequently, if the wage changes by $d w$ and the number of goods changes by $d N$, that person's utility changes by

$$
d u(l)=b l e^{-b w l / N} d w+d N\left(1-e^{-b w l / N}\left(1+\frac{b w l}{N}\right)\right),
$$

where $1-e^{-b w l / N}\left(1+\frac{b w l}{N}\right)>0 .{ }^{17}$

Therefore, if $N$ is held fixed, wage reductions triggered by productivity improvements unambiguously reduce the welfare of workers-only if everybody owns enough shares may welfare go up for all agents. When one endogenizes the number of goods, as in the preceding subsection, $N$ goes up with $a$. That effect may in principle be large enough to compensate for wage reductions: people lose in physical purchasing power but gain in product variety. However, for arbitrarily poor agents, the gains from diversity are second order relative to the loss from reduced purchasing power. To see this, note that for $l$ small, $\partial u / \partial N=1-e^{-b w l / N}\left(1+\frac{b w l}{N}\right) \approx \frac{b^{2} w^{2} l^{2}}{2 N^{2}} \ll \partial u / \partial w=b l$. Thus, poor enough people only care about physical purchasing power, not diversity. Regardless of the response of $N$ to $a$, some agents will lose from productivity growth in the Marxian zone, provided there exist agents endowed with an arbitrarily low level of $l{ }^{18}$ This property comes from the fact that $u^{\prime}(c)$ remains bounded as $c$ approaches zero: When one consumes very little of each good, utility is near-linear, and the value of diversity is negligible. In principle, it may not hold if $u$ is such that $\lim _{c \rightarrow 0} u^{\prime}(c)=+\infty$, although there is no tractable functional form for $u$ which satisfies both that condition and the limited needs property.

\footnotetext{
${ }^{17}$ Proof: the function $h(x)=1-x e^{-x}-e^{-x}$ satisfies $h(0)=0$ and $h^{\prime}(x)=x e^{-x}>0$ for $x>0$. Therefore, $h(x)>0$ for all $x>0$.

${ }^{18}$ In the context of the previous subsection's model, these agents will indeed specialize in production as long as the $h / l$ ratio goes up with $s$.
} 


\subsection{Balanced vs. unbalanced growth}

We have seen that TFP growth depresses the relative, and possibly absolute wage of production workers, assuming that it was the only source of technical progress.

In this section I want to point out that these sharp predictions only hold because growth is unbalanced, i.e. productivity increases in the material goods sector but not in the innovation sector. If the cost of producing new blueprints falls at the same rate as the cost of producing output, one can construct a balanced growth path where wages for researchers and workers grow at that common rate (hence all wages trend upward, and inequality is constant), while a Marxian zone may still exist in that a once-and-for all increase in productivity in the output sector may permanently reduce worker's wages relative to their previous growth path.

To see this, let us describe how the model can be extended to construct a growth model, restricting ourselves to the case where the economy's endowments in $H$ and $L$ are fixed and exogenous.

The inflow of new blueprints is determined by the supply of intellectual labor $H$. The number of varieties $N_{t}$ evolves according to

$$
\dot{N}_{t}=H / \gamma_{t}
$$

where $\gamma_{t}=\gamma_{0} e^{-g t}$ is the unit cost (in terms of creative labor) of producing a good. ${ }^{19}$

The static model described in the previous section is still valid intratemporally, with the following modifications. First, total factor productivity $a$ is now time-varying, and thus denoted by $a_{t}=a_{0} e^{g t}$. Second, expenditure at $t$, which must replace income in the intratemporal demand functions for individual goods, must now be consistent with intertemporal optimization

\footnotetext{
${ }^{19}$ Contrary to what is assumed in Grossman and Helpman (1991), $\gamma_{t}$ is exogenous and there is no externality from the aggregate number of goods to $\gamma_{t}$.
} 
by consumers. That is, we now assume that consumer $j$ maximizes

$$
U_{j}=\int_{0}^{+\infty} u_{j t} e^{-\rho t} d t
$$

where $u_{j t}$ is defined by (1) (with a time subscript appended to $c_{i j t}$ ), and where maximization takes place subject to the intertemporal budget constraint

$$
\int_{0}^{+\infty} R_{j t} e^{-\int_{0}^{t} r_{u} d u} d t \leq W_{j}
$$

where $R_{j t}$ now denotes total expenditure on goods at date $t, W_{j}$ is the agent's total wealth and $r_{u}$ the instantaneous real interest rate at date $u$. We are still analyzing a symmetrical equilibrium where all goods have the same price. ${ }^{20}$ Our price normalization is unchanged, $p_{i t}=1$, and consumption of each good by consumer $j$ thus remains determined by $c_{i j t}=c_{j t}=R_{j t} / N_{t}$. As $u_{j t}=N_{t}\left(1-e^{-b R_{j t} / N_{t}}\right)$, we see that the Euler equation corresponding to (14)-(15) is

$$
\dot{R}_{j t} / R_{j t}=\frac{r+b \dot{N}_{t} / N_{t}-\rho}{b}
$$

Thus, expenditure grows at the same rate for all consumers, so that one may replace $R_{j t}$ by aggregate expenditure $Y_{t}$ in (16).. In equilibrium, summing expenditures over all goods, we again get that $Y_{t}=a_{t} L$. Since in steady state $\dot{N} / N=g=\dot{a} / a$, we clearly have

$$
\rho=r
$$

\footnotetext{
${ }^{20}$ To prove that such an equilibrium exists, one may proceed in two steps. First, show that if a static symmetrical equilibrium exists for $Y=a_{t} L$, then $r=\rho$ and $R_{t}=a_{t} L$ is necessary and sufficient for market clearing and intertemporal optimization in steady state, as maximizing (14) subject to (15) is a standard, concave, optimal control problem. Then, check that a symmetrical static equilibrium exists for $Y=a_{t} L$, by applying something like Proposition 1, or assume a representative consumer, to rule out deviations where firms exclude some consumers.
} 
The intra-period demand functions and pricing rules are unchanged. Consequently, the wage equation (8) still holds. We rewrite it for convenience, adding time indices:

$$
w_{t}=a_{t}\left(1-b a_{t} L / N_{t}\right)
$$

In steady state, $a / N$ is a constant, so wages grow at rate $g$. On the other hand, the formula implies that a once-and-for all increase in the level of $a$ (i.e. an increase in $a_{0}$ if one assumes $a_{t}=a_{0} e^{g t}$ ) may reduce the level of wages by a fixed amount in the new steady state relative to the old one.

Inventors get a patent which gives them monopoly power over the production of the new variety for ever. The value of such a patent, $V_{t}$, evolves according to

$$
r_{t} V_{t}=\pi_{t}+\dot{V}_{t}
$$

where $\pi_{t}$ is the profit of a monopoly at $t$, which is still given by (9).

Competition in the $\mathrm{R}$ and $\mathrm{D}$ sector guarantees that the cost of producing a variety equals the value of a patent:

$$
\gamma_{t} \omega_{t}=V_{t}
$$

We can see readily that in steady state,

$$
\omega_{t}=\frac{b}{\rho \gamma_{t}}\left(\frac{L a_{t}}{N_{t}}\right)^{2}
$$

Noting that in steady state one must have $N_{t}=H /\left(\gamma_{0} g\right) \cdot e^{g t}$, this can be rewritten as

$$
\omega_{t}=\frac{b}{\rho} \gamma_{0} e^{g t}\left(\frac{L a_{0} g}{H}\right)^{2} .
$$

An interesting aspect is that higher growth rates increase the return to creativity relative to productivity: 


$$
\frac{\omega_{t}}{w_{t}}=\frac{\frac{b}{\rho} \gamma_{0}\left(\frac{L a_{0} g}{H}\right)^{2}}{a_{0}\left(1-b a_{0} \gamma_{0} g L / H\right)} .
$$

The explanation is as follows. Because goods are only accumulated gradually through invention, an acceleration in the growth rate reduces the equilibrium number of goods relative to the productivity level, in a fashion similar to the negative effect of growth on the equilibrium capital/output ratio in standard growth models. As a result, one consumes more of each good, so that firms can charge higher markups. This redistributes income in favor of firms, and eventually in favor of creative labor whose wage is indexed on profits.

To conclude, this section has shown that balanced growth is feasible if productivity in inventing new goods grows in line with productivity in producing existing goods. If the latter grows faster than the former, then the economy eventually enters a Marxian zone with falling wages, for the reasons explained at the beginning of the paper.

Along a balanced growth path, productivity gains in the innovation sector make sure that enough new goods are introduced to match increased consumption possibilities, so as to prevent consumption of each good and thus markups from going up.

\section{Applications}

In this section, I show how the model can shed light on various policy debates. First, I consider what happens in the model if real wages are rigid, i.e. set by unions. That may be especially relevant for continental Europe. I show that rather than reducing wages, productivity growth then unambiguously increases unemployment. Second, I look at the impact of 'globalization', i.e. international trade, and show that if, under autarchy, relative productivity in poor countries is lower than their relative number of varieties, then trade reduce wages in the poorest countries, as workers there face higher markups 
because of the low elasticity of demand coming from rich countries. Finally, I present some illustrative evidence in favour of the model by looking at comovements between consumption per good and inequality.

\subsection{Unions}

It is often argued that in continental Europe, inequality has not risen, in particular because wages are rigid. One may then ask how the previous results would be changed if wages were rigid. To analyze this, we consider the role of labor unions. Going back to the simple static model of section 1 , let us assume that the wage within each firm is determined by a monopoly union which maximizes the total wage bill. The firm takes wages as given, while unions set wages prior to price-setting by firms, i.e. fully take into account the effect of their wage on their firm's prices. Total employment is now endogenous and must adjust to make firms' and unions' behaviour compatible with each other.

Equation (4) gives us the demand function for each firm, from which the demand curve for labor from the point of view of the union can be easily obtained:

$$
l_{i}=l\left(w_{i}\right)=\frac{c_{i}}{a}=c_{i}=\frac{-\frac{1}{b} \ln \frac{p_{i}}{b}+\frac{\int_{0}^{N} \frac{p_{m}}{b} \ln \frac{p_{m}}{b} d m}{\int_{0}^{N} p_{m} d m}+\frac{Y}{\int_{0}^{N} p_{m} d m}}{a},
$$

where $p_{i}$ is an implicit function of $w_{i}$, determined by the firm's optimal pricing policy (5), which we rewrite for convenience:

$$
-\frac{1}{b} \ln \frac{p_{i}}{b}+\frac{\int_{0}^{N} \frac{p_{m}}{b} \ln \frac{p_{m}}{b} d m}{\int_{0}^{N} p_{m} d m}+\frac{Y}{\int_{0}^{N} p_{m} d m}=\frac{p_{i}-w_{i} / a}{b p_{i}} .
$$

The union setting wages for product $i$ thus maximizes $w_{i} l\left(w_{i}\right)$, under (18) and (19). The FOC is $l\left(w_{i}\right)+w_{i} l^{\prime}\left(w_{i}\right)=0$. Let us again look for a symmetrical equilibrium where $p_{m}=1$, for all $m$. Then the union's first order condition can be written

$$
-\frac{1}{b} \ln p_{i}+\frac{Y}{N}=\frac{w_{i}}{b p_{i}} \frac{d p_{i}}{d w_{i}}
$$


where $d p_{i} / d w_{i}$ is computed from (19), yielding

$$
\frac{d p_{i}}{d w_{i}}=\frac{1}{a(2-b Y / N)}
$$

Substituting, and imposing now $p_{i}=1$, we get

$$
\begin{aligned}
w_{i} & =w=a \frac{b Y}{N}\left(2-b \frac{Y}{N}\right) \\
& =a \frac{b a L}{N}\left(2-b \frac{a L}{N}\right)
\end{aligned}
$$

while (19) still implies the same equilibrium relationship between $w$ and $L$ :

$$
w=a\left(1-b \frac{a L}{N}\right)
$$

The equilibrium values of wages and employment are now jointly determined by (21) and (22). We get:

$$
w=a k,
$$

where $k=(\sqrt{5}-1) / 2$, and

$$
L=\frac{N(1-k)}{a b}
$$

Consequently, wages are proportional to productivity and there is no Marxian zone. Insiders appropriate a fraction $k$ of productivity gains. Wages can grow proportionally to productivity only if markups remain constant. As growth in the consumption of each good pushes markups up, for union wages to be compatible with price-setting ${ }^{21}$, consumption must not rise when productivity goes up. Therefore, equilibrium employment must fall proportionally with productivity!

\footnotetext{
${ }^{21}$ That unemployment adjusts to make wage formation compatible with price formation is a cornerstone of modern macroeconomics. See Blanchard (1986), Layard et al. (1990). Here productivity growth increases markups and thus the natural rate of unemployment. Unemployment remains constant, however, if this is matched by an equiproportional increase in the number of goods.
} 
By generating unemployment, this unionized economy prevents expenditure from going up as productivity increases: markups do not increase and the Marxian zone is not reached, at the cost of higher unemployment.

Note that in this unionized world, people would quite naturally believe in the 'end of work', as productivity increases always reduce employment. Proponents of the ' 'end of work' view would mistakenly interpret the lump of output as a "law", whereas it is a consequence of the war of mark-ups between firms and unions.

Furthermore, even if firms were to charge a constant markup, employment would still be inversely proportional to productivity. The reason is that the declining elasticity property would still apply to labor demand, thus prompting unions to increase their wage demands as consumption goes up. To see this, assume that rather than being produced by a monopoly, each good $i$ is produced by a large number of perfectly competitive firms. Wages in sector $i$, however, are still set by a single monopoly union. One then clearly has $p_{i}=w_{i} / a$. To compute a symmetrical equilibrium, one then just has to substitute $w=a$ for $(22)$ and $d p_{i} / d w_{i}=1 / a$ in (20). We now get

$$
\begin{aligned}
w & =a ; \\
L & =\frac{N}{a b} .
\end{aligned}
$$

Wages are still proportional to $a$ and employment falls proportionally with productivity.

Of course, the property that productivity growth generates an equiproportional fall in employment in a unionized economy is extreme: one eventually expects union power to fall with employment, and people can find jobs in the non unionized sector. But the results accord strikingly with often-heard complaints about productivity growth reducing employment, and the fact that these complaints are more common in the rigid labor markets of continental Europe than in Anglo-Saxon countries. 


\subsection{Globalization}

The model may also have striking implications regarding the impact of 'globalization', i.e. international trade, on wages. While the empirical literature has somewhat discredited the idea that trade is responsible for the observed rise in inequality (see e.g. Lawrence and Slaughter (1993)), the typical prediction is that trade should exert a downward pressure on wages of the unskilled in rich countries, because this factor is more abundant in poor countries. Thus if one could blame it for increased inequality in rich countries, at least the poorest in poor countries would gain, which is somewhat reassuring.

I show that this prediction may well be reversed, i.e. unskilled wages may rise in rich countries and fall in poor countries, so that globalization may lead to falling inequality in rich countries and rising inequality in poor countries $^{22}$. What matters is the relative abundance of labor, adjusted for productivity, compared to the number of varieties.

I assume that there are two countries, home and foreign. Variables relating to the latter are denoted by a star. Consumers' preferences are still defined by (1). There is a fixed endowment of labor in each country, $L, L^{*}$, which is immobile. There are initially $N_{A}$ firms at home and $N_{A}^{*}$ firms abroad, but firms can freely relocate. In equilibrium, there is an endogenous mass $N$ of firms producing at home, and $N^{*}=N_{A}+N_{A}^{*}-N$ firms producing abroad. Goods are traded in a worldwide integrated market. The two countries differ in their productivity $a$ and $a^{*}$.

The demand for any good $i$ (now indexed between 0 and $N+N^{*}$, with good $i$ produced at home iff $0 \leq i<N)$ is now given by

$$
c_{i}=-\frac{1}{b} \ln \frac{p_{i}}{b}+\frac{\int_{0}^{N_{A}+N_{A}^{*}} \frac{p_{m}}{b} \ln \frac{p_{m}}{b} d m}{\int_{0}^{N_{A}+N_{A}^{*}} p_{m} d m}+\frac{Y+Y^{*}}{\int_{0}^{N_{A}+N_{A}^{*}} p_{m} d m}=c\left(p_{i}\right),
$$

where $Y$ (resp. $\left.Y^{*}\right)$ is national income at home (resp. abroad). The first-order condition for optimal pricing reads:

\footnotetext{
${ }^{22}$ Thus, the effect of globalization on the rich country is the opposite of the effect of productivity growth.
} 


$$
-\frac{1}{b} \ln \frac{p_{i}}{b}+\frac{\int_{0}^{N_{A}+N_{A}^{*}} \frac{p_{m}}{b} \ln \frac{p_{m}}{b} d m}{\int_{0}^{N_{A}+N_{A}^{*}} p_{m} d m}+\frac{Y}{\int_{0}^{N_{A}+N_{A}^{*}} p_{m} d m}=\frac{p_{i}-w_{i} / a_{i}}{b p_{i}},
$$

where $w_{i}=w, a_{i}=a$, if the firm is located at home, and $w_{i}=w^{*}, a_{i}=a^{*}$, if it is located abroad.

This defines the optimal $p_{i}$ as a function of local marginal cost: $p_{i}=$ $p\left(w_{i} / a_{i}\right)$. Note that the $p$ function does not depend on country-specific characteristics, because firms face the same world demand regardless of their location.

Mobility of firms between the two countries implies that profits must be equalized

$$
(p(w / a)-w / a) c(p(w / a))=\left(p\left(w^{*} / a^{*}\right)-w^{*} / a^{*}\right) c\left(p\left(w^{*} / a^{*}\right)\right) .
$$

The model is closed by defining national incomes:

$$
Y=\int_{0}^{N} p_{m} c_{m} d m, Y^{*}=\int_{N}^{N_{A}^{*}+N_{A}} p_{m} c_{m}
$$

and writing down equilibrium in the labor market:

$$
a L=\int_{0}^{N} c_{m} d m ; a L^{*}=\int_{N}^{N_{A}^{*}+N_{A}} c_{m} d m
$$

Clearly, one can construct a symmetrical equilibrium where $w / a=w^{*} / a^{*}$, $c_{m}=\frac{a L+a^{*} L^{*}}{N_{A}+N_{A}^{*}}, \forall m, N=\frac{a L}{a L+a^{*} L^{*}}$ and $p=p^{*}=1$, where the latter equality is a normalization. Equations (23)-(25) allow to compute equilibrium wages in both countries:

$$
w=a\left(1-b \frac{a L+a^{*} L^{*}}{N_{A}+N_{A}^{*}}\right)
$$

Under autarchy, one simply applies the model of section 1 to get (with the prices of all goods again set to one):

$$
\begin{aligned}
& w_{A}=a\left(1-b \frac{a L}{N_{A}}\right) ; \\
& w_{B}=a\left(1-b \frac{a^{*} L^{*}}{N_{A}^{*}}\right) .
\end{aligned}
$$


Hence, trade increases wages at home and reduces them abroad if

$$
\frac{a L}{N_{A}}>\frac{a^{*} L^{*}}{N_{A}^{*}},
$$

and vice-versa. The country where wages fall is the country where consumption of each good is initially lower, i.e. the country where the number of firms is higher relative to total productive capacity; or, equivalently, the country where markups are lower under autarchy than under trade. By increasing the output of firms based in that country, globalization moves it closer to the Marxian zone, and its workers suffer from the higher markups applied by its firms to new customers who care less about the good. From a factual point of view, this may well be the poorest country-one may think it has fewer varieties, but also a lower value of $a .^{23}$ This result has a Stolper-Samuelson flavor: the country where wages go up when moving from autarchy to trade is the country where labor (as defined by $a L$, i.e. adjusted for productivity) is more abundant relative to the number of varieties.

Note that these results hold if wages are expressed in physical terms, i.e. they ignore the fact that wages can purchase more utility under trade because they are spent on a greater variety of goods. If these effects are reintroduced, one can show that in the country where wages fall, workers gain provided their labor endowment is larger than a critical value ${ }^{24}$.

Again, these results are all due to the evolution of markups. If markups were constant and equal to $\mu$, one could check that the solution would be the same, except for wages which would be given by $w_{k}=a_{k} / \mu$, and therefore would be equal to their level under autarchy. Globalization would then not affect wages in physical terms and all workers would gain because it allows

\footnotetext{
${ }^{23}$ Another interesting implication is that productivity growth in one country unambiguously reduces wages in the other one.

${ }^{24}$ It is easy to check that, if that country is 'foreign', this critical level is the value of $l$ which satisfies

$$
\frac{1-e^{-w^{*} l}}{1-e^{-w_{A}^{*} l}}=\frac{N_{A}^{*}}{N_{A}+N_{A}^{*}} .
$$
}


them to access a greater variety of goods. ${ }^{25}$

\subsection{A glance at the data}

The model's general message is that inequality between creative workers and production workers goes up with the markup, which itself is an increasing function of $a L / N=c$, the amount of each good consumed by the average consumer,. If this phenomenon has contributed to inequality trends, then we should observe some correlation between this ratio and inequality. Figure 5 plots the evolution of these two quantities over time in the United States. The $a L / N$ ratio was measured as the ratio between consumption per capita in volume, from the OECD Economic Outlook database, and a measure of the stock of trademarks, constructed from the US Patent and Trademark office database. ${ }^{26}$. Inequality is defined as the $80 / 20$ percentile income ratio, computed from the Luxembourg Income Study database. ${ }^{27}$ Figure 5 suggests that the increase in inequality during the eighties was preceded by an increase in $c$. Similarly, the moderate decline in inequality after 1995 was preceded by a fall in $c$. This picture suggests that movements in $c$ lead movements in inequality that go in the same direction. One may conjecture that the increase in the returns to skill eventually led to an acceleration of innovation which contributed to a rise in $N$ relative to $a$, and eventually engineered the reversal in inequality in the latter part of the nineties. Clearly, one cannot ascribe $100 \%$ of the change in inequality to changes in $c$; for example, the

\footnotetext{
${ }^{25}$ This section's results are somewhat related to recent findings by Matsuyama (2000), who considers the impact of productivity growth and globalization when poorer countries are specialized in goods with a lower income elasticity.

26

The stock was constructed iteratively, on the basis on the flow of total trademark registrations granted per year, with a depreciation rate of $5 \%$. The intial value of the stock at date $t=1981$ was assumed equal to the steady state one, $R_{1981} / 0.05$, where $R_{1981}$ is the number of registration granted in 1975 . (http://www.uspto.gov/web/offices/com/annual/2000/00tables.pdf).

${ }^{27}$ The available years are: 1974, 1979, 1986, 1991, 1994, 1997, 2000. Numbers for intermediate years were linearly interpolated.
} 
rise in $c$ in the early eighties is moderate compared to the corresponding rise in inequality, while the fall in $c$ in the nineties is much larger than the fall in inequality after 1995. Nevertheless, the comovements between inequality and lagged values of $c$ are consistent with the model.

Does the model explain cross-country differences in inequality trends? A substantial part of these differences is probably due to differences in institutions, while some authors also point to differences in factor endowments. ${ }^{28}$ However, there may also be a role for the mechanism discussed in this paper. Figure 6 compares the evolution of $c$ in France ${ }^{29}$, where inequality has essentially remained constant, and in the US, where it has increased up to 1995. As we can see, $c$ falls more rapidly (and earlier) in France than in the US, in accordance with the model.

While the evidence presented here will not convince any skeptic, it is broadly consistent with the view that inequality goes up as total productive capacity rises more than proportionally to the number of varieties.

\section{Conclusion and assessment}

The idea that general technical progress is harmful to labor and may lead to "The end of work" is typically inconsistent with general equilibrium analysis. General technical progress makes one unit of labor worth more in terms of consumption goods. It is very hard to escape this conclusion in a wellspecified model. One can get transitory negative effects on labor if retraining is needed (as in Aghion and Howitt, 1994), or if technical change is asymmetrical and labor reallocation is costly (as in Cohen and Saint-Paul, 1994), but these effects are unlikely to be very long lived. In this paper I have shown, in the context of a standard general equilibrium model of monopolistic compe-

\footnotetext{
${ }^{28}$ Beaudry and Green (2003).

${ }^{29}$ French data were taken from the WIPO data set, available at http://www.wipo.int/ipstats/en/publications/25_years/index.htm.

This data set is less reliable than the USPTO dataset; in particular, there is an aberrant break in the French data between 1995 and 1996. For this reason, Figure 6 is confined to the 1981-1995 period.
} 
tition between differentiated goods, that if utility is finite, productivity will affect markups in a way that is systematically detrimental to wages in the tangible goods sector.

The model also sheds light on a number of policy issues. For example, in, the Marxian zone, "Malthusian" policies that oppose the adoption of new technologies ${ }^{30}$, or prevent productivity from rising by imposing constraints such as work rules or working time reductions, would seem to "work" in that they would benefit wages ${ }^{31}$, even though such policies are dominated by mere redistribution to workers. Another implication is that profit-sharing policies, as advocated by Weitzman (1984), would help make sure that all agents benefit from productivity growth.

Before concluding, it is worth repeating that wages have increased by

\footnotetext{
${ }^{30}$ In Das Kapital, Chapter 15, Marx gives some interesting historical examples of such policies:

"In the 17th century nearly all Europe experienced revolts of the workpeople against the ribbon-loom, a machine for weaving ribbons and trimmings, called in Germany Bandmühle, Schnurmühle, and Mühlenstuhl. These machines were invented in Germany. Abbé Lancellotti, in a work that appeared in Venice in 1636, but which was written in 1579, says as follows: "Anthony Müller of Danzig saw about 50 years ago in that town, a very ingenious machine, which weaves 4 to 6 pieces at once. But the Mayor being apprehensive that this invention might throw a large number of workmen on the streets, caused the inventor to be secretly strangled or drowned." In Leyden, this machine was not used till 1629; there the riots of the ribbon-weavers at length compelled the Town Council to prohibit it. "In hac urbe," says Boxhorn (Inst. Pol., 1663), referring to the introduction of this machine into Leyden, "ante hos viginti circiter annos instrumentum quidam invenerunt textorium, quo solus plus panni et facilius conficere poterat, quan plures aequali tempore. Hinc turbae ortae et querulae textorum, tandemque usus hujus instrumenti a magistratu prohibitus est." After making various decrees more or less prohibitive against this loom in 1632, 1639, \&c., the States General of Holland at length permitted it to be used, under certain conditions, by the decree of the 15th December, 1661. It was also prohibited in Cologne in 1676, at the same time that its introduction into England was causing disturbances among the workpeople. By an imperial Edict of 19th Feb., 1685, its use was forbidden throughout all Germany. In Hamburg it was burnt in public by order of the Senate. The Emperor Charles VI., on 9th Feb., 1719, renewed the edict of 1685, and not till 1765 was its use openly allowed in the Electorate of Saxony. This machine, which shook Europe to its foundations, was in fact the precursor of the mule and the power-loom, and of the industrial revolution of the 18th century. It enabled a totally inexperienced boy, to set the whole loom with all its shuttles in motion, by simply moving a rod backwards and forwards, and in its improved form produced from 40 to 50 pieces at once. "

${ }^{31}$ Indeed, such policies are often advocated by people whose view of the world is similar to the "end of work" arguments.
} 
several orders of magnitude over the very long run. This is consistent with the basic Solow model, and it is what happens along the balanced growth paths that we have studied. The Marxian productivity paradox highlighted in this paper certainly does not apply to the experience of modern economies over the last two centuries. However, what is more plausible is that an economy experiences stagnation or decline in wages for several decades as the outcome of productivity growth and the "banalization" of consumption. This is what has been observed recently and what this model is aimed at explaining. In the longer run, such a decline will be reversed, because productivity will also increase in the knowledge sector, and also because public authorities are likely to force a reduction in markups by competition policies such as anti-trust laws, a mechanism we have ignored in our analysis by assuming that monopoly power is intact in response to changes in productivity. 


\section{References}

Acemoglu, D. "Why do new technologies complement skills? Directed technical change and wage inequality", Quarterly Journal of Economics, Nov. 1998

Acemoglu, D. "Changes in unemployment and wage inequality: an alternative theory and some evidence", American Economic Review, Dec. 1999

Aghion, P. and Howitt, P. (1994). "Growth and Unemployment", Review of Economic Studies

Baumol, W. J. (1967). Macroeconomics of unbalanced growth: the anatomy of urban crisis. American Economic Review, 57, pp. 415-426

Baumol, W. J. (1985). "Productivity policy and the service sector". In R. P. Inman (ed.) Managing the service economy: prospects and problems. Cambridge: Cambridge University Press

Beaudry, P. and Green, D. (2003). "Wages and employment in the US and Germany: What explains the difference ?", American Economic Review

Benhabib, J. and Bisin, A. (2001). "Advertising, mass consumption, and Capitalism", mimeo, NYU.

Blanchard, O. (1986). "The wage-price spiral", Quarterly Journal of Economics

Caselli, F. "Technological Revolutions", American Economic Review, March 1999

Cohen, D. and Saint-Paul, G.(1994). "Uneven technical progress and job destruction", CEPR Discussion paper.

Dixit, A. and Stiglitz, J. (1977). "Monopolistic competition and optimum product diversity", American Economic Review, 67(3), pp. 297-308

Falkinger, J. (1990). "On growth along a hierarchy of wants", Metroeconomica, 3, pp. 209-223

Falkinger, J. (1994). "An Engelian model of growth and innovation with hierarchic consumer demand and unequal outcomes", Ricerche Economiche, 48, pp. $123-139$ 
Foellmi, R. and Zweimüller, J. 2002. "Heterogeneous Mark-ups, Demand Composition, and the Inequality-Growth Relation,", mimeo, Zurich University

Grossman, G. and Helpman, E. (1991). Innovation and Growth in the Global Economy. Cambridge MA: MIT Press

Juhn, C., Murphy, K. M. and Pierce, B. "Wage Inequality and the Rise in Returns to Skill", Journal of Political Economy, Volume 101, Issue 3, June 1993, pp. 410-442

Katz, L. and Murphy, K. "Changes in Relative Wages, 1963-1987: Supply and Demand Factors", Quarterly Journal of Economics, Volume 107, Issue 1, February 1992, pp. 35-78

Krusell, P., Ohanian, L., Rios-Rull, J.V. and Violante, G. (2000). "Capitalskill complementarity and inequality", Econometrica

Layard, R., Nickell, S. and Jackman , R. (1990). Unemployment, Oxford U. Press

Lawrence, R.Z. and Slaughter, M.J. (1993). "International Trade and American Wages in the 1980s: Giant Sucking Sound or Small Hiccup?" Brookings Papers on Economic Activity; 0(0), Microeconomics 1993, pp. 161-210.

Levy, F. and Murnane, R. J. (1992). "U.S. Earnings Levels and Earnings Inequality: A Review of Recent Trends and Proposed Explanations", Journal of Economic Literature, Volume 30, Issue 3, September 1992, pp. 1333-1381

Matsuyama, K. (2000). "A Ricardian model with a continuum of goods under nonhomothetic preferences: Complementarities, income distribution, and north-south trade", Journal of Political Economy, 108(6), pp. 1093-1120

Morrison, C. (1992). "Markups in U.S. and Japanese manufacturing: a short-run econometric analysis", Journal of Business and Economic Statistics, 10(1), pp. 51-63.

Nevo, A. (1999). "Measuring market power in the ready-to-eat cereal industry", CPC WP \#99-01, UC Berkeley.

Reich, R. (1992). The Work of Nations : Preparing Ourselves for 21st Century Capitalism. Vintage Books. 
Rifkin, J. (1996). The End of Work : The Decline of the Global Labor Force and the Dawn of the Post-Market Era. JP Tarcher.

Rosen, S. (1981). "The economics of superstars", American Economic Review, 71(5), pp. 845-58

Weitzman, M. (1985). "The Simple Macroeconomics of Profit Sharing" American Economic Review; 75(5), December 1985, pp. 937-53.

Zeira, J. (1998). "Workers, machines, and economic growth", Quarterly Journal of Economics, 1998 


\section{Appendix}

Proof of Proposition 1: In order to prove that a symmetrical equilibrium indeed exists, we need to prove that $p_{i}=1$ is the optimal price for a producer if all other firms charge $p=1$.

First, note that the demand function for good $i$ is

$$
\begin{aligned}
& D\left(p_{i}\right)=-\frac{1}{b} \ln p_{i}+\frac{Y}{N}, \text { for } p_{i} \leq 1 \\
& D\left(p_{i}\right)=\int_{\frac{N \ln p_{i}}{b}}^{+\infty} g(R)\left(-\frac{1}{b} \ln p_{i}+\frac{R}{N}\right) d R, \text { for } p_{i}>1
\end{aligned}
$$

If $p_{i}>1$, then only consumers with an income greater than $\frac{N \ln p_{i}}{b}$ consume good $i$.

Next, the profit function for firm $i$ is

$$
\pi\left(p_{i}\right)=\left(p_{i}-w / a\right) D\left(p_{i}\right)
$$

Differentiating, and substituting (6), we get that for $p_{i} \leq 1$,

$$
\pi^{\prime \prime}\left(p_{i}\right)=-\frac{1}{b p_{i}}-(1 / b-Y / N) / p_{i}^{2}<0
$$

Thus, $\pi($.$) is concave for p_{i} \leq 1$, so that $\pi(1) \geq \pi\left(p_{i}\right)$ in this zone.

Consider now the zone where $p_{i}>1$. One has

$$
\pi^{\prime}\left(p_{i}\right)=\int_{N \ln p_{i} / b}^{+\infty} g(R)\left(-\frac{1}{b} \ln p_{i}+\frac{R}{N}-\frac{p_{i}-w / a}{b p_{i}}\right) d R .
$$

A sufficient condition is that this expression is nonpositive for all $p_{i}>1$, which, changing variables and using again (??), can be rewritten as

$$
F(z)=\int_{z}^{+\infty} g(R)\left(-\frac{z}{N}+\frac{R}{N}-\frac{1}{b}+(1 / b-Y / N) e^{-b z / N}\right) d R \leq 0, \forall z>0
$$

Note that $F(0)=0$, which is just a restatement of the property that $\pi^{\prime}(1)=0$.

Condition (26) can be rewritten as 


$$
\int_{z}^{+\infty} g(R) R d R \leq\left(z+\frac{N}{b}\left(1-e^{-b z / N}\right)+Y e^{-b z / N}\right)(1-G(z)) .
$$

Given that $Y<N / b$, a sufficient condition for (27) to hold is clearly (10). Q.E.D.

Proof of Lemma 1: Assume (11) holds. Then

$$
\begin{aligned}
E(R & \mid R \geq z)=\frac{\int_{z}^{+\infty} u g(u) d u}{1-G(z)} \\
& =\frac{\int_{0}^{+\infty}(v+z) g(v+z)}{1-G(z)} \\
& \leq \int_{0}^{+\infty}(v+z) g(v) d v \\
& =Y+z .
\end{aligned}
$$

Q.E.D.

Derivation of (13). We now prove that (11) holds for the equilibrium distribution of income if the $h($.$) and l($.$) functions are given by (13).$

Let us denote by $R^{*}=\omega h\left(s^{*}\right)=w l\left(s^{*}\right)$ the income of the critical worker. The distribution of income $G(R)$ is given by

$$
\begin{aligned}
G(R) & =h^{-1}(R / \omega), \text { if } R \geq R^{*} ; \\
& =l^{-1}(R / w), \text { if } R \leq R^{*}
\end{aligned}
$$

Hence,

$$
\begin{aligned}
g(R) & =\frac{1}{\omega h^{\prime}\left(h^{-1}(R / \omega)\right)}, \text { if } R \geq R^{*} ; \\
& =\frac{1}{w l^{\prime}\left(l^{-1}(R / w)\right)}, \text { if } R \leq R^{*} .
\end{aligned}
$$

For condition (11) to hold, we then need that
A. $l^{\prime}\left(l^{-1}(u+v)\right)\left(1-l^{-1}(v)\right) \geq l^{\prime}\left(l^{-1}(u)\right)$, if $u+v \leq R^{*} / w$
B. $h^{\prime}\left(h^{-1}(u+v)\right)\left(1-h^{-1}(v)\right) \geq h^{\prime}\left(h^{-1}(u)\right)$, if $u \geq R^{*} / \omega$ and $v \geq R^{*} / \omega$ 
C. $h^{\prime}\left(h^{-1}(u+v)\right)\left(1-l^{-1}(\omega v / w)\right) \geq w l^{\prime}\left(l^{-1}(\omega u / w)\right) / \omega$, if $u+v \geq R^{*} / \omega$, $u \leq R^{*} / \omega, v \leq R^{*} / \omega$

D. $h^{\prime}\left(h^{-1}(u+v)\right)\left(1-l^{-1}(\omega v / w)\right) \geq h^{\prime}\left(h^{-1}(u)\right)$, if $u+v \geq R^{*} / \omega, u \geq$ $R^{*} / \omega, v \leq R^{*} / \omega$

E. $h^{\prime}\left(h^{-1}(u+v)\right)\left(1-h^{-1}(v)\right) \geq w l^{\prime}\left(l^{-1}(\omega u / w)\right) / \omega$, if $u+v \geq R^{*} / \omega$, $u \leq R^{*} / \omega, v \geq R^{*} / \omega$

Let us now turn to specification (13). For $h() / l()$ to be increasing, it must be that

$$
\frac{\beta}{\lambda}>\frac{h_{0}}{l_{0}}
$$

Furthermore,

$$
\frac{w}{\omega}=\frac{h_{0}-\frac{\ln \left(1-s^{*}\right)}{\lambda}}{l_{0}-\frac{\ln \left(1-s^{*}\right)}{\beta}} \in\left(\frac{h_{0}}{l_{0}}, \frac{\beta}{\lambda}\right) .
$$

The condition $\omega h\left(s^{*}\right)=w l\left(s^{*}\right)$ implies

$$
-\ln \left(1-s^{*}\right)=\frac{w l_{0}-\omega h_{0}}{\omega / \lambda-w / \beta}
$$

The income of the critical worker is thus:

$$
R^{*}=\frac{w \omega\left(l_{0}-\lambda h_{0} / \beta\right)}{\omega-\lambda w / \beta} .
$$

And we have

$$
\begin{aligned}
l^{\prime}\left(l^{-1}(x)\right) & =\frac{e^{\beta\left(x-l_{0}\right)}}{\beta} ; h^{\prime}\left(h^{-1}(x)\right)=\frac{e^{\lambda\left(x-h_{0}\right)}}{\lambda} \\
1-l^{-1}(x) & =e^{-\beta\left(x-l_{0}\right)} ; 1-h^{-1}(x)=e^{-\beta\left(x-h_{0}\right)} .
\end{aligned}
$$

Case A: substituting these formulae, we see that the inequality is equivalent to

$$
1 \geq e^{-\beta l_{0}}
$$

which is true. 
Case B: Similarly, we get

$$
1 \geq e^{-\gamma h_{0}}
$$

which is true.

Case C: the inequality is equivalent to

$$
\frac{w}{\omega} \leq \frac{\beta}{\lambda} e^{(u+v)(\lambda-\beta \omega / w)+2 \beta l_{0}-\lambda h_{0}}
$$

As $\omega / w>\lambda / \beta$, the RHS is decreasing in $u+v$. It is always larger than its minimum value, reached at $u+v=2 R^{*} / \omega=2\left(\beta l_{0}-\lambda h_{0}\right) /(\beta \omega / w-\lambda)$. Substituting into the RHS of (28), we see that it is satisfied for all the relevant $u$ and $v$ if

$$
\frac{w}{\omega} \leq \frac{\beta}{\lambda} e^{\lambda h_{0}}
$$

which is true, as $\frac{w}{\omega}<\frac{\beta}{\lambda}$.

Case D. The inequality is now equivalent to

$$
1 \leq e^{(\lambda-\beta \omega / w) v} e^{\beta l_{0}} .
$$

Again, the RHS reaches its minimum value for the largest possible value of $v$ in this zone, $v=R^{*} / \omega=\left(\beta l_{0}-\lambda h_{0}\right) /(\beta \omega / w-\lambda)$. Substituting, we find

$$
1 \leq e^{\lambda h_{0}}
$$

which is true again.

Case E. The inequality is equivalent to

$$
\frac{w}{\omega} \leq \frac{\beta}{\lambda} e^{\beta l_{0}} e^{(-\beta \omega / w+\lambda) u} .
$$

The minimum of the RHS is reached at $u=R^{*} / \omega=\left(\beta l_{0}-\lambda h_{0}\right) /(\beta \omega / w-$ $\lambda)$. Thus we need to have

$$
\frac{w}{\omega} \leq \frac{\beta}{\lambda} e^{\lambda h_{0}},
$$


which is again satisfied.

The condition in lemma 1 is therefore satisfied by the distribution of income corresponding to the symmetrical equilibrium with $l()$ and $h()$ defined by (13). 


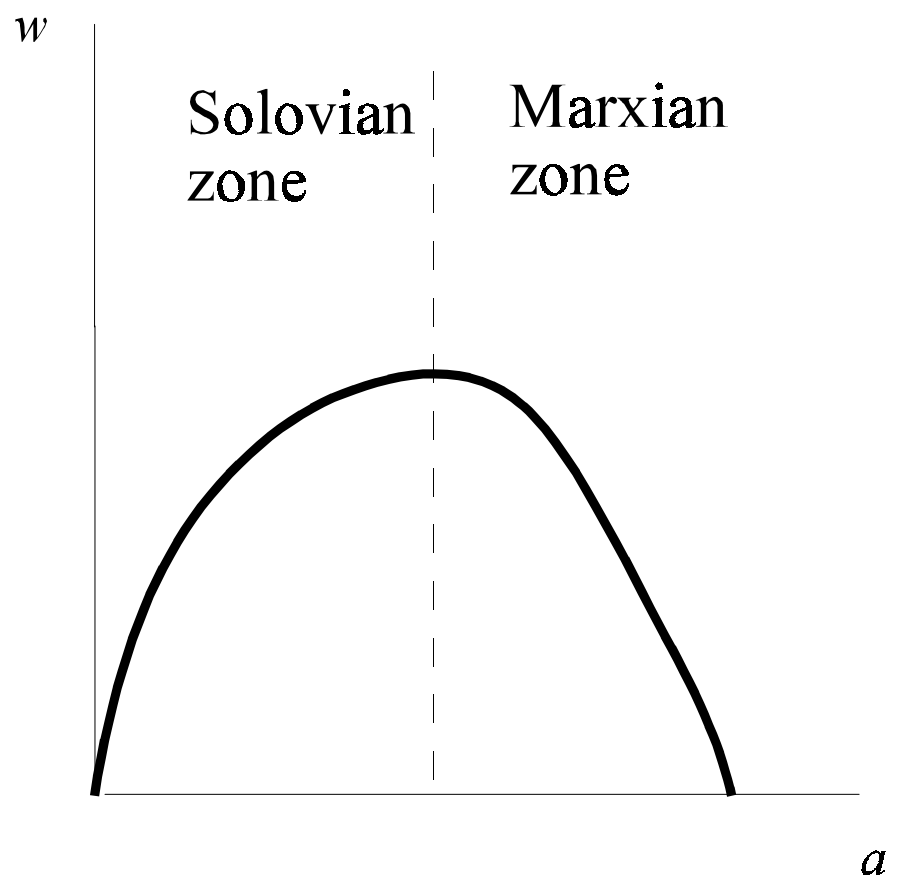

Figure 1: Effect of productivity on wages 
Figure 2: Effect of TFP on relative wages

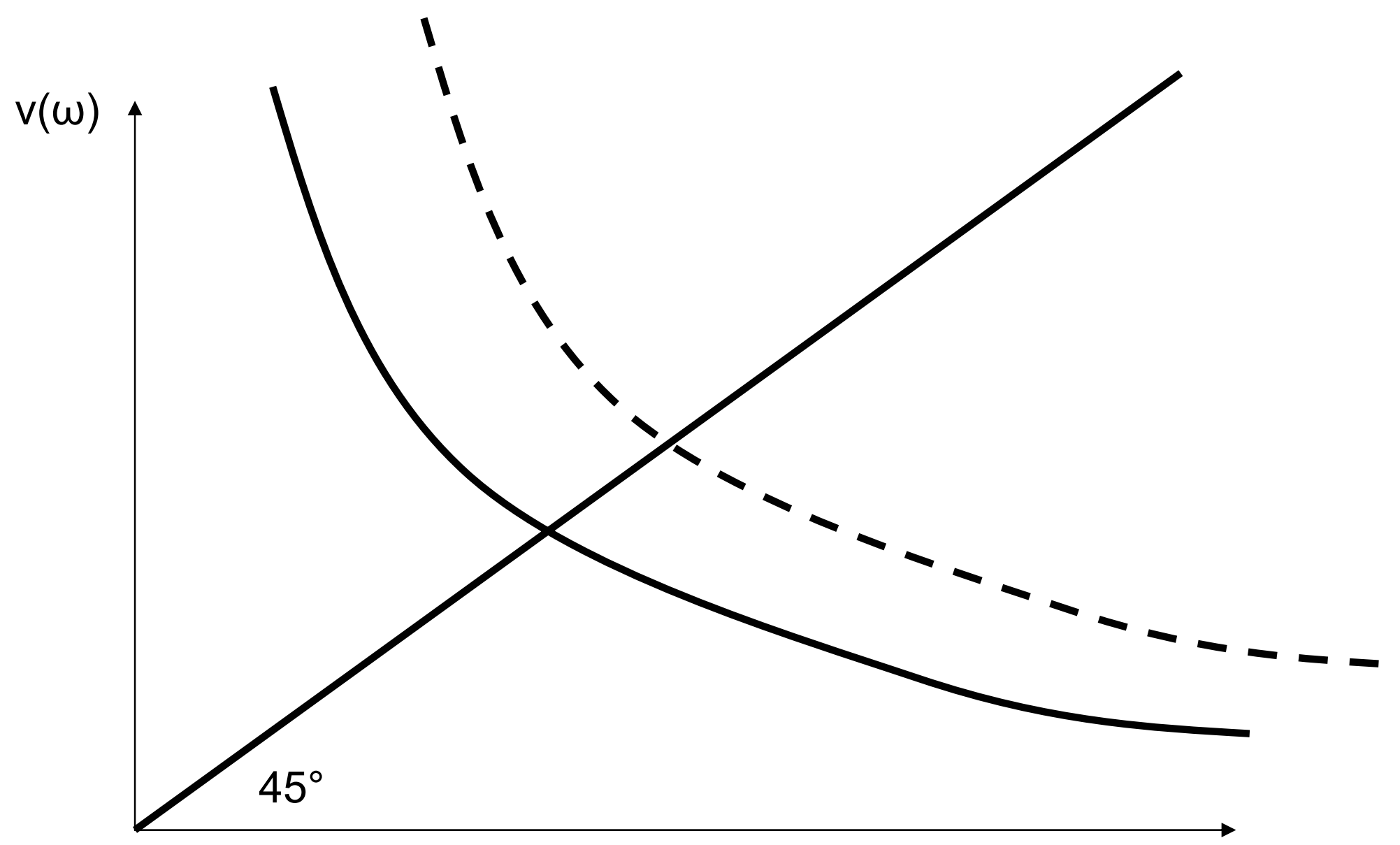

$w / \omega$ 
Figure 3 wage distribution

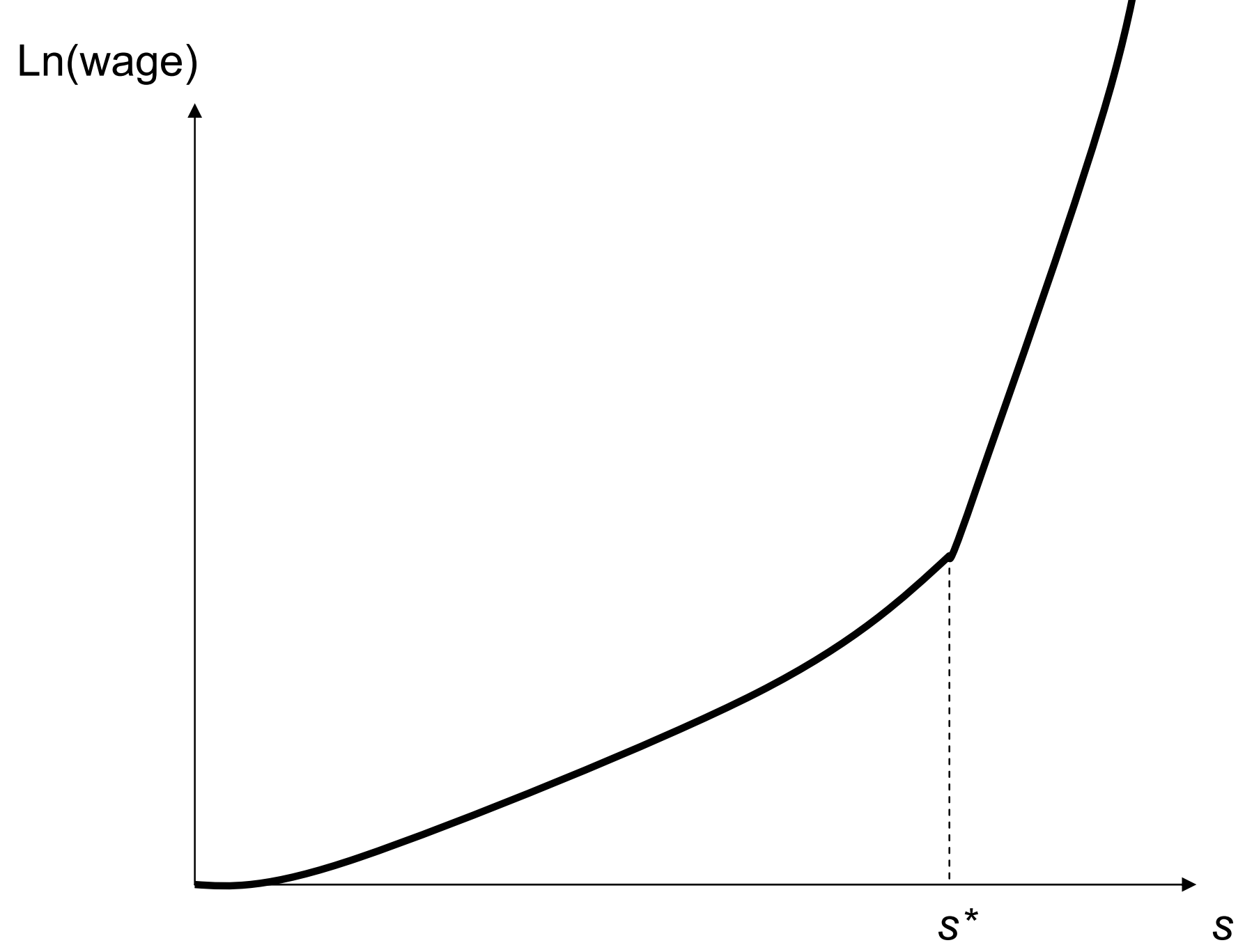


Figure 4a: effect of TFP growth on wages, Marxian zone

Ln(wage)

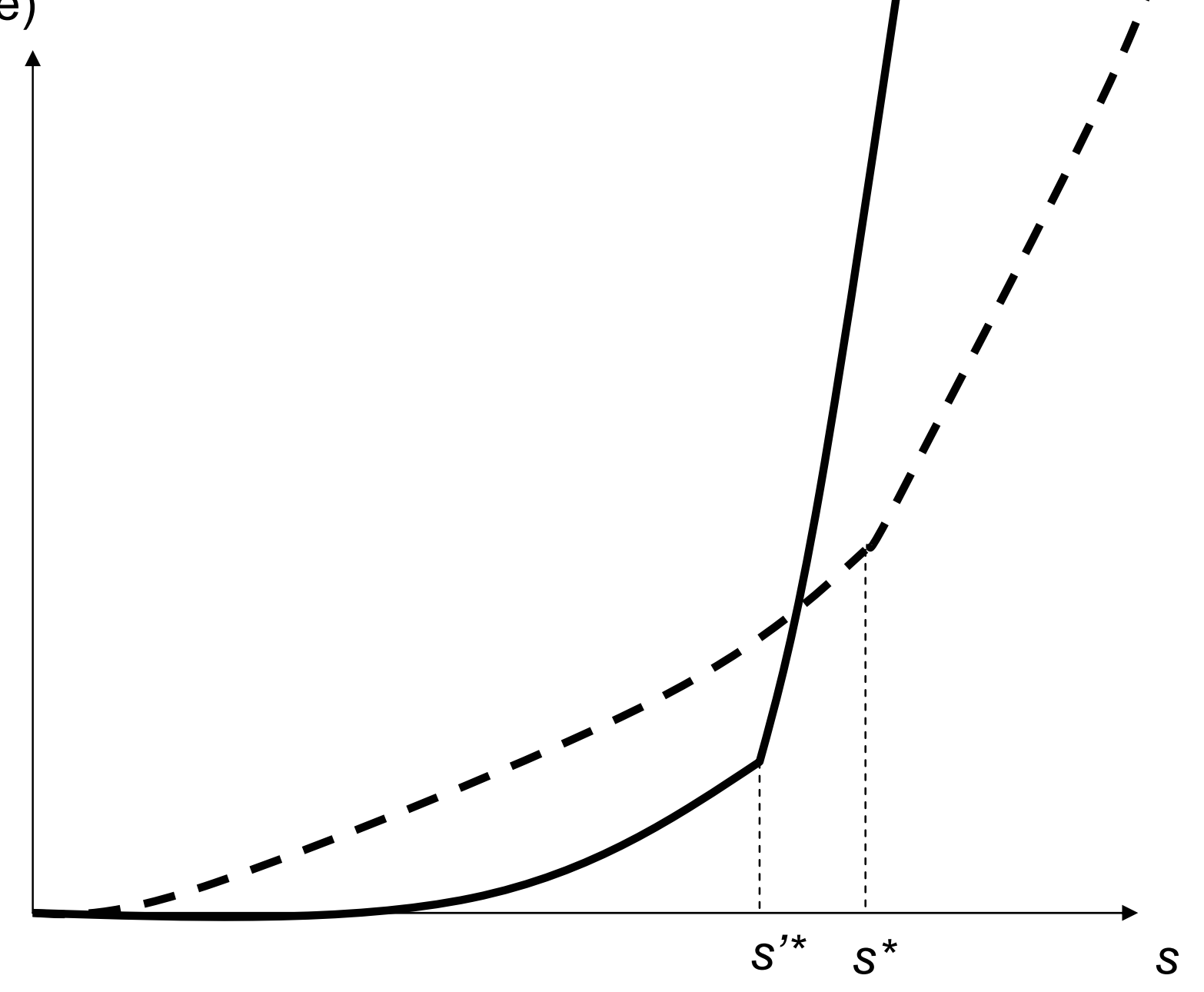


Figure 4b: effect of TFP growth on wages, Solovian zone

Ln(wage)

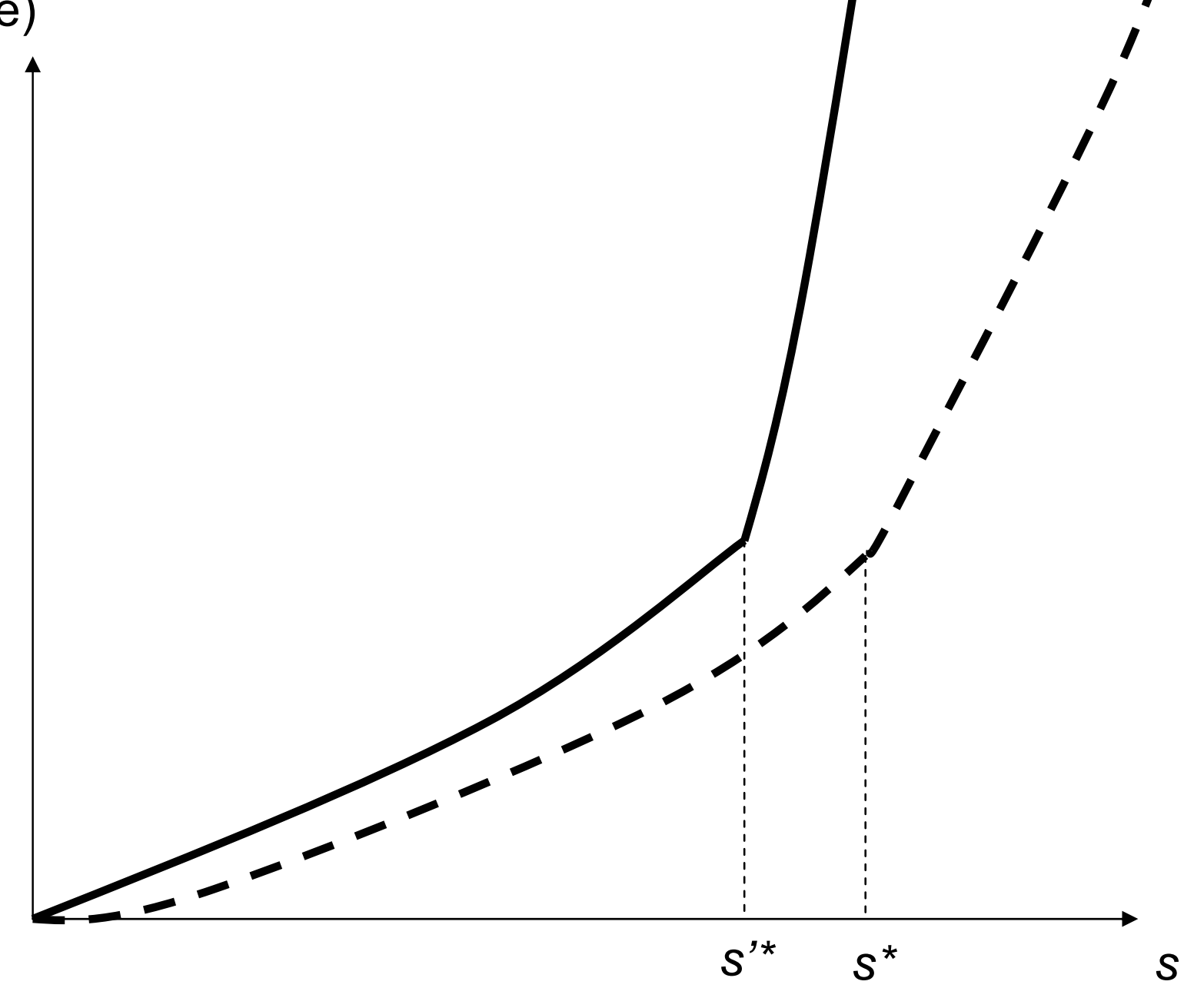


Figure 5: consumption per trade mark and inequality in the United States

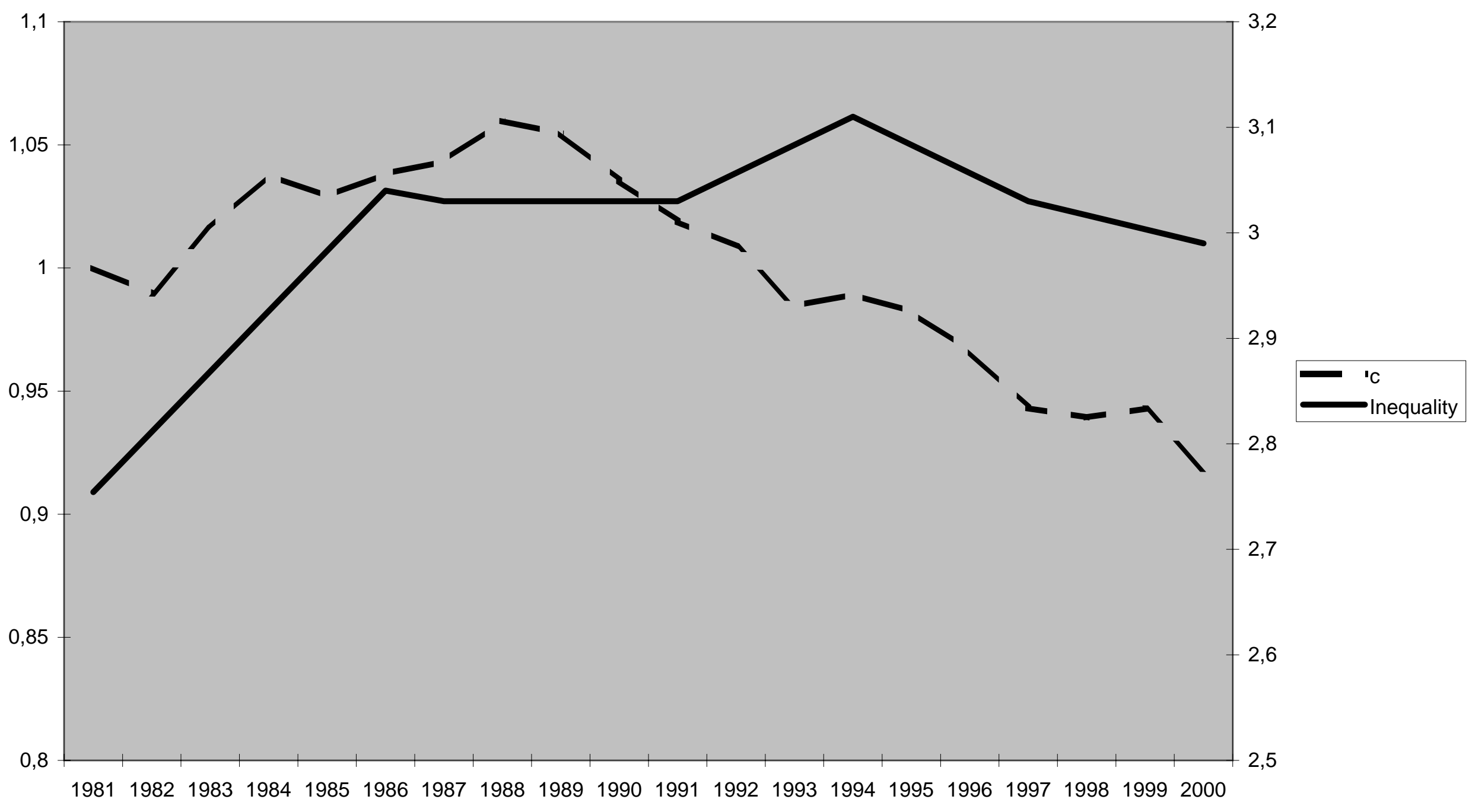


Figure 6: The evolution of $c$ in France and in the US

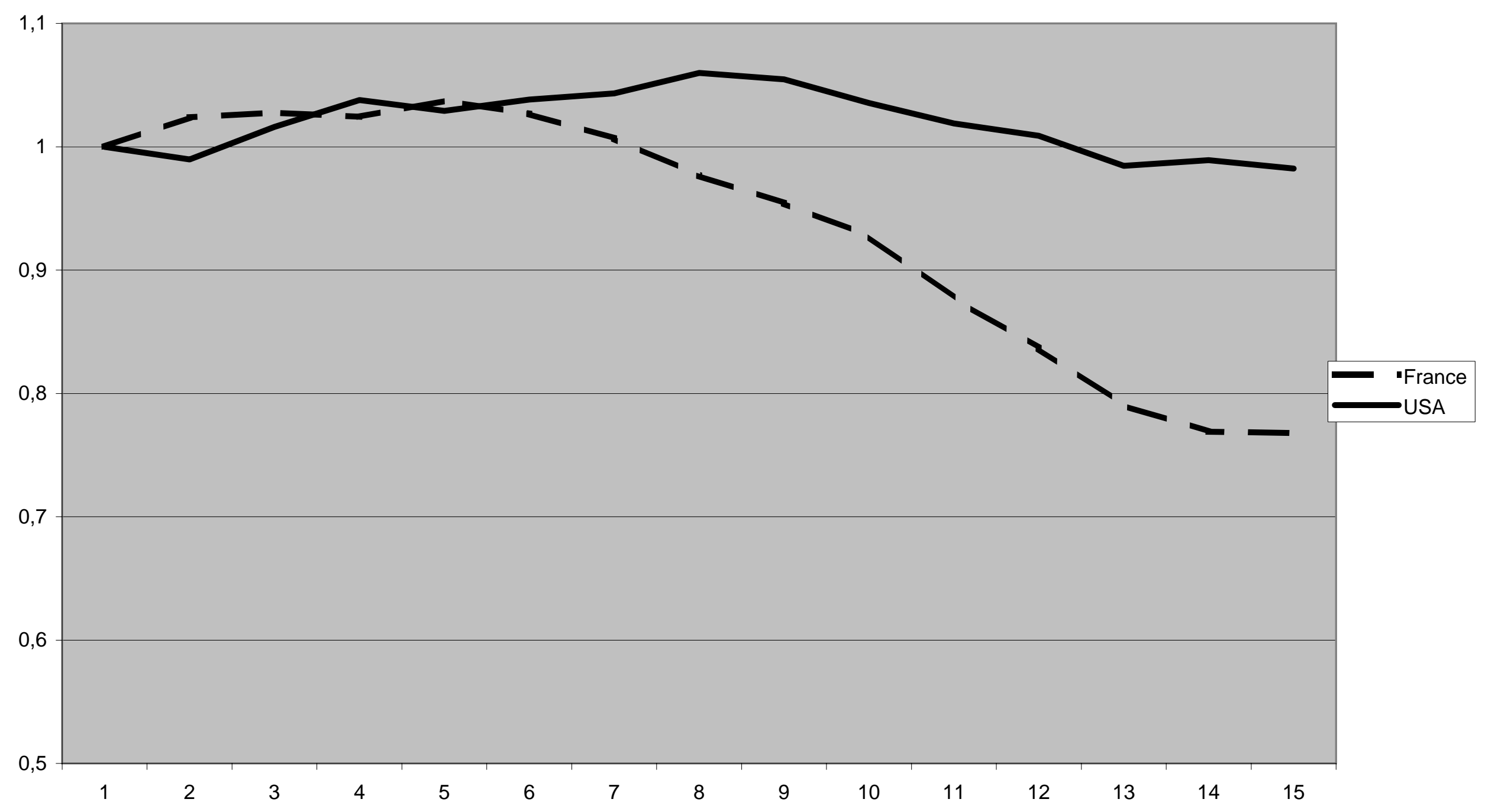

